\title{
Analyses of Predictive Factors Associated with Hypocalcemia and Elevated iPTH with Normocalcemia after Ultrasound-guided Radiofrequency Ablation for Primary Hyperparathyroidism
}

\section{Hui-Hui Chai}

Graduate Department, Bengbu Medical College, Bengbu, Anhui

\section{Yu Zhao}

Department of Endocrinology, Zhejiang Provincial People's Hospital, Hangzhou Medical College, Hangzhou, Zhejiang

\section{Rui-Zhong Ye}

Department of Ultrasound, Zhejiang Provincial People's Hospital, Hangzhou Medical College, Hangzhou, Zhejiang

\section{Zeng Zeng}

Department of Ultrasound, Zhejiang Provincial People's Hospital, Hangzhou Medical College, Hangzhou, Zhejiang

\section{Zheng-Xian Zhang}

Department of Ultrasound, Hangzhou Hospital of Traditional Chinese Medicine, Hangzhou, Zhejiang

Qiao-Hong Hu

Department of Ultrasound, Zhejiang Provincial People's Hospital, Hangzhou Medical College, Hangzhou, Zhejiang

\section{Hai-Su Pang}

Department of Ultrasound, Hangzhou Hospital of Traditional Chinese Medicine, Hangzhou, Zhejiang Cheng-Zhong Peng ( $\triangle$ pcz001@126.com )

Graduate Department, Bengbu Medical College, Bengbu, Anhui

\section{Research Article}

Keywords: hypocalcemia, normocalcemia, PHPT, US-guided RFA

Posted Date: April 20th, 2021

DOI: https://doi.org/10.21203/rs.3.rs-422854/v1 
License: (c) (i) This work is licensed under a Creative Commons Attribution 4.0 International License. Read Full License 


\section{Abstract \\ Purpose}

To assess the feasibility of ultrasound-guided (US-guided) radiofrequency ablation (RFA) for primary hyperparathyroidism (PHPT) and determine predictive factors for hypocalcemia and elevated serum intact parathyroid hormone(ePTH) with normocalcemia after ablation.

\section{Materials and Methods}

Between January 2015 and January 2021, data from 44 patients with PHPT who were treated with USguided RFA were retrospectively evaluated. Serum intact parathyroid hormone(iPTH), total calcium (Ca), phosphorus, alkaline phosphatase (ALP), and 25-hydroxyvitamin $\mathrm{D}_{3}\left(25(\mathrm{OH}) \mathrm{D}_{3}\right)$ levels and the volume of the abnormal enlarged parathyroid glands were recorded before RFA. Changes in IPTH and Ca levels at 1 and 3 days, and, 1, 3, and 6 months after ablation were recorded.

\section{Results}

Overall, thirteen patients developed hypocalcemia 1-3 days after RFA. ePTH with normocalcemia developed in 17 patients 1 month after RFA. Thirty-two patients were followed up for more than 6 months, and 27 of these patients had sustained normalized values for both serum iPTH and Ca levels more than 6 months after RFA. There were significantly more patients who developed hypocalcaemia, when the baseline ALP was greater than $261.5 \mathrm{U} / \mathrm{L}$ (sensitivity $61.5 \%$, specificity $100.0 \%$ ). The risk of ePTH decreased by $21.7 \%$ for every $1 \mathrm{ng} / \mathrm{mL}$ increase in $25(\mathrm{OH}) \mathrm{D}_{3}$. The risk of ePTH was increased when a patient's serum iPTH was higher than $172.4 \mathrm{pg} / \mathrm{mL}$ (sensitivity $88.2 \%$, specificity $76.2 \%$ ).

\section{Conclusions}

US-guided RFA is feasible for clinical management of PHPT patients. Hypocalcaemia following RFA was associated with higher pre-RFA serum ALP levels. Elevated iPTH levels with normocalcemia at 1 month after RFA were associated with pre-RFA vitamin D deficiency and higher baseline iPTH levels. Patients with higher serum ALP and iPTH and lower $25(\mathrm{OH}) \mathrm{D}_{3}$ levels before RFA need to be managed carefully and monitored closely after RFA of PHPT.

\section{Introduction}

Primary hyperparathyroidism (PHPT) is an endocrine disorder caused by the spontaneous production of excess parathyroid hormone by at least one of the four parathyroid glands(1). Classical PHPT is associated with hypercalcemia and involves target organs, such as the kidneys and bones $(2,3)$. In North 
America and Europe, the incidence of asymptomatic PHPT has increased 4-5 fold since 1970 due to routine screening of serum calcium ( $\mathrm{Ca}$ ) measurements. Thus, the clinical presentation of PHPT changes from symptomatic to asymptomatic (4). The incidence rate varies from $0.4-82$ per 100,000 people $(5,6)$. Approximately $75-85 \%$ of patients with PHPT have a single parathyroid adenoma, $2-12 \%$ have two adenomas, $<1-2 \%$ have three adenomas, and $<1-15 \%$ have four or more adenomas. Parathyroid carcinoma accounts for $<1 \%$ of $\operatorname{cases}(7)$.

Parathyroidectomy is considered to be the main therapy for $\operatorname{PHPT}(8,9)$. At present, the effect and efficiency of surgical treatment is better than that of medical therapy and it is more economical(10). If performed by experienced surgeons, the cure rates of hyperparathyroidism could be above $95 \%$ and surgical complications are few(8). However, some patients, such as frail elderly patients, do not meet the surgical criteria or refuse surgery. The risks of surgery and anesthesia are higher for those patients, and other treatments need to be applied for the treatment of primary hyperparathyroidism(11). In recent years, the application of thermal ablation in the parathyroid gland has been attempted and has become an alternative therapy for patients with PHPT who do not meet the surgical criteria or refuse surgery $(12,13)$. Radiofrequency ablation (RFA) was first reported in 2002 by Hänsler et al. for the treatment of single parathyroid adenoma in humans, producing satisfactory biochemical results and leading to improvements in clinical symptoms(14). To date, only a limited number of studies have reported on patients undergoing RFA for PHPT $(15,16,17)$. Ultrasound-guided (US-guided) RFA has been used for the treatment of secondary hyperparathyroidism in our department since 2013. Promising improved serum iPTH and normalized serum Ca levels have been achieved when treating secondary hyperparathyroidism by US-guided RFA $(18,19)$.

In our department, US-guided RFA has also been used for the treatment of PHPT. Changes in the serum total $\mathrm{Ca}$ and iPTH levels were notable findings in the post-ablative period. These changes included significant hypocalcemia and the rebound in serum iPTH levels. Similar phenomena have been observed after surgery $(20,21)$. Postoperative hypocalcemia was defined as a serum total Ca level $<2.11 \mathrm{mmol} / \mathrm{L}$. As the traditional definition, ePTH is defined as iPTH exceeding the upper limit of normal in weeks following treatment in which the patient had normocalcemia $(22,23)$. Few studies have investigated the predictive factors of post-ablative hypocalcemia and ePTH. In this study. The purpose of this study was to evaluate the safety and feasibility of US-guided RFA for PHPT and to investigate the predictive factors of post-ablative hypocalcemia and ePTH.

\section{Materials And Methods}

Our study was approved by the Human Ethics Review Committee of the Zhejiang Provincial People's Hospital and Hangzhou Hospital of Traditional Chinese Medicine. Written informed consent was obtained from all patients enrolled prior to ablation. We confirm that all methods were performed in accordance with the relevant guidelines and regulations.

\section{Study Design}


Clinical and biochemical data of patients with PHPT treated with RFA at Zhejiang Provincial People's Hospital and Hangzhou Hospital of Traditional Chinese Medicine from January 2015 to January 2021 were retrospectively collected and analyzed for this study. Overall, RFA was performed in 51 patients with PHPT, of whom 7 patients were excluded. The reasons for exclusion were as follows: 2 (3.92\%) with double nodules, 1 (1.96\%) with four hyperplastic glands, and $4(7.84 \%)$ with incomplete detailed laboratory examination or data that was not recorded. Thus, 44 patients with a single nodule were included in this study. In this study, the parathyroid glands of all patients were scanned and localized with technetium 99-m-labeled sestamibi single-photon emission computed tomography (99mTc-sestamibi SPECT) and US imaging.

Patients included in our study with those criteria: (1) Consistent with the diagnoses of PHPT; (2) Positive 99mTc-sestamibi SPECT and US scan results; (3) Refusing surgery or failing to meet surgical standards. Exclusion criteria included: (1) Data on serum iPTH and total Ca values were unavailable for two or more successive follow up points after RFA; (2) Being treated with cinacalcet, calcitonin or bisphosphonates; (3) A hoarse voice or any vocal cord movement abnormalities; (4) Patients with thyroid carcinoma; (5) The gland was suspected of malignant tumors, for example the boundary was not clear, had an irregular shape, was lobulated, had microcalcification, or had swollen lymph nodes around the tumor lesions and the surrounding tissue boundary was unclear; (6) Severe abnormal coagulant function abnormality test, such as a prothrombin time $>18 \mathrm{~s}$, prothrombin activity $<60 \%$, or a platelet count $<60 \times 10^{9}$.

\section{Equipment}

US-guided RFA was performed using grayscale imaging with an iU22 US scanner and a high-frequency linear probe (L12-5) (Philips, The Netherlands), while contrast-enhanced ultrasound (CEUS) with a highfrequency linear probe (L9-3) was used to assess the extent of the ablation area. Thermal ablation of hyperplastic parathyroid glands was performed using an RFA system (VIVA; STARmed, Goyang, Korea), including a radiofrequency generator and an 18-gauge monopolar internally cooled electrode with an output of 30-45 W power. The radiofrequency electrode had a $1.0 \mathrm{~cm}$ active tip with an inner-cooling system (VIVA pump; STARmed).

\section{Procedures}

US-guided RFA was performed by a single experienced radiologist with more than 20 years of experience in interventional US. Ultrasonography was performed to determine the optimal approach, and CEUS of the parathyroid gland was performed to determine the location and outer edge of the lesion. The patient was placed in the supine position with the neck extended. After neck skin disinfection, the skin and subcutaneous tissue were injected with $1 \%$ lidocaine for local anesthesia. Then, 10 to $100 \mathrm{~mL}$ of $5 \%$ dextrose solution was injected into the area around the parathyroid nodule (parathyroid gland and the thyroid, carotid artery, internal jugular vein, and recurrent laryngeal nerve crossing areas) to create a buffering zone at least $5 \mathrm{~mm}$ in depth as insulators (Fig. 1). Then, the RFA needle electrode was inserted into the parathyroid gland near the distal capsule under real-time sonographic guidance. The thermal ablation effect showed hyperechoic regions within the coagulated tissue. The entire targeted glands were 
ablated by moving the electrode from one area to another area until the coagulation was complete. Immediate effect evaluation was mainly performed using CEUS for the assessment of the treatment response. If the non-enhanced zone covered the ablated nodule, ablation was discontinued; otherwise, additional ablation was continued. During the procedure, the radiologist assessed whether the patient experienced pain and hoarseness or voice changes through a conversation. If voice changes occurred, the radiologist immediately stopped the treatment.

Technical steps of Us-guided RFA. (a, b) First, technetium-sestamibi scan and US examination revealed a $29.6 \times 16.9 \times 13.1 \mathrm{~mm}$ PHPT nodule inferior to the right lobe of the thyroid gland (arrows). (c) Color doppler image shows abundant blood flow signals (arrows) in the PHPT nodule. (d) There was nonuniform hyperenhancement (arrows) PHPT nodule on CEUS. (e, f) Insertion of a 21-gauge needle (arrows) to inject $5 \%$ dextrose solution to create a safe distance $>5 \mathrm{~mm}$ in depth (green dotted line) between PHPT nodule and the vital structures of the neck. (g) Insertion of 18-gauge internally cooled electrode into the back of the PHPT nodule generates thermal energy and mobile ablation was performed with hyperechoic area (arrows) emerging inside nodule. (h) Color doppler image shows a significant reduction of the vascular signals (arrows) immediately after RFA. (i) When non-enhancement area covered PHPT nodule (arrows) on CEUS, treatment was ended.

\section{Data collection}

Serum iPTH, total Ca, phosphorus, ALP, $25(\mathrm{OH}) \mathrm{D}_{3}$ levels, and the pathological parathyroid gland volume were tested and recorded before ablation. The volume of each pathological parathyroid gland was calculated using the sphere formula $(V=$ length $\times$ width $\times$ depth $\times \pi / 6)$.

The reference intervals used for the different parameters were as follows: standard serum ALP: $50-135$ U/L; iPTH: $15-65$ pg/ml; total Ca: $2.11-2.52 \mathrm{mmol} / \mathrm{L}$.

In this study, the hypocalcemia group comprised those patients with the lowest serum total Ca level (< $2.11 \mathrm{mmol} / \mathrm{L}$ ) within 72 hours after treatment; the patients without hypocalcemia were those with the lowest serum total Ca level $(\geq(2.11 \mathrm{mmol} / \mathrm{L})$ within 72 hours after RFA. The ePTH group comprised those patients with elevated serum iPTH levels and normal serum Ca levels, while the normal PTH group comprised those with normal serum iPTH and Ca levels 1 month after RFA.

\section{Follow-Up and Outcomes}

The follow-up time points were 1 and 3 days, and 1, 3, and 6 months after RFA. Changes in blood biochemical tests, including serum iPTH and Ca levels, were collected before treatment and at each follow-up point. Serum phosphorus and ALP levels were recorded at last follow-up. Any adverse events observed during the follow-up period were also noted. Persistent hyperparathyroidism (P-PHPT) was classified as serum iPTH and Ca levels above the upper limit of normal within 6 months after RFA. Finally, recurrent hyperparathyroidism (R-PHPT) was defined as hypercalcemia after at least 6 months of normocalcemia following RFA (24).

\section{Statistical analysis}


All statistical analyses were performed using SPSS software (version 26.0, IBM Corp. Armonk, NY, USA). Continuous data were presented as mean \pm standard deviation or median and interquartile range (Q25 Q75) and categorical variables were displayed as a frequency. Serum total $\mathrm{Ca}$, phosphorus, iPTH, and ALP levels were compared at baseline and at the last follow-up using paired-sample t-tests and pairedsample Wilcoxon signed-rank tests. The Mann-Whitney U test or Student's t-test were used to compare differences in the continuous variables between the groups. Chi-squared test was performed to compare categorical variables between groups. Binary logistic regression analysis was performed for the variables with $P<0.05$ in the univariate analysis. Statistical significance was set at $p<0.05$.

\section{Results}

\section{Patient characteristics}

In this study, 44 patients included 15 males and 29 females, with age from 17 to 87 years old; Overall, 19 patients had kidney stones, 3 had ureteral stones, 11 had bone pain, 15 had osteoporosis, 2 had pathological fractures, and 4 patients had asymptomatic PHPT. Table 1 summarizes the baseline characteristics of the patients and nodules before RFA. All patients had high baseline serum iPTH levels, which varied from $80.00-1964.00 \mathrm{pg} / \mathrm{mL}$. Thirty-Seven patients had baseline serum total Ca levels above the upper limit of normal, and Ca levels varied from 2.20-3.71 mmol/L. All patients had abnormal enlarged parathyroid glands in normal location, and the volume of ablated glands varied from 0.05-6.97 $\mathrm{ml}$. The baseline characteristics before RFA are summarized in Table 1.

Table 1

The baseline characteristics of patients and PHPT nodules before US-guided RFA. 


\begin{tabular}{|c|c|c|}
\hline \multicolumn{2}{|l|}{ Features } & \multirow{2}{*}{$\begin{array}{l}\text { Data }(n=44) \\
58.45 \pm 14.90\end{array}$} \\
\hline Characteristics of Patients & Age(y) & \\
\hline & Male/Female & $15 / 29$ \\
\hline \multirow[t]{7}{*}{ Clinical manifestations } & Asymptomatic & 4 \\
\hline & Symptomatic & 40 \\
\hline & Nephrolithiasis & 22 \\
\hline & Ostealgia & 11 \\
\hline & Fracture & 3 \\
\hline & Osteoporosis & 15 \\
\hline & Neurocognitive disorders & 1 \\
\hline \multirow[t]{5}{*}{ Laboratory data } & iPTH (pg/mL) & 176.15(135.20-323.33) \\
\hline & Total Ca (mmol/L) & $2.73(2.57-2.83)$ \\
\hline & Phosphorus (mmol/L) & $0.87 \pm 0.15$ \\
\hline & $\operatorname{ALP}(U / L)$ & $124.50(82.50-206.00)$ \\
\hline & $25(\mathrm{OH}) \mathrm{D}_{3}(\mathrm{ng} / \mathrm{ml})$ & $15.85 \pm 6.59$ \\
\hline \multirow[t]{6}{*}{ Characteristics of PHPT nodules } & Volume (mL) & $0.56(0.25-0.97)$ \\
\hline & Location of nodules & \\
\hline & Superior left & 7 \\
\hline & Inferior left & 16 \\
\hline & Superior right & 8 \\
\hline & Inferior right & 13 \\
\hline \multicolumn{3}{|c|}{$\begin{array}{l}\text { PHPT = primary hyperparathyroidism, US-guided = ultrasound-guided, RFA = radiofrequency ablation } \\
\text { iPTH = intact parathyroid hormone, ALP = alkaline phosphatase, Total } C a=\text { Total calcium, } 25(\mathrm{OH}) \mathrm{D} \\
=25 \text {-hydroxyvitamin } \mathrm{D}_{3} .25(\mathrm{OH}) \mathrm{D}_{3} \text {, phosphorus values and age are presented as mean } \pm \text { standard } \\
\text { deviation; Total } \mathrm{Ca}, \mathrm{PTTH}, \mathrm{ALP} \text { values and volume are median and interquartile range. }\end{array}$} \\
\hline
\end{tabular}

\section{Treatment effect}

Treatment outcome

\section{Efficacy within 6 months}


All 44 patients were followed up for 1-3 days. Thirty-nine patients were followed up for 1 month; Thirtyeight patients were normocalcemic and 1 patient remained hypercalcemic 1 month after the ablation. Post-RFA serum iPTH and total Ca levels were significantly lower at 1 and 3 days, and 1, 3, and 6 months than those before RFA (all, P $<0.001$ ). Notably, the median serum iPTH levels were significantly elevated at 1 month compared with 1-3days post-ablation, then decreased and tended to be stable at 3 and 6 months after RFA. Conversely, there were $7(15.9 \%), 2(4.5 \%), 1(2.5 \%), 0(0 \%)$ and $0(0 \%)$ patients of hypercalcemia at 1 day, 3days, 1 month, 3 month and 6 months, respectively. The lowest serum total Ca arose in 1-3 days after RFA and 13 of these patients developed hypocalcemia. The changes in serum iPTH and Ca levels at each follow-up within 6 months are summarized in Table 2.

Table 2

Changes in serum iPTH and total Ca levels at each follow-up within 6 months after RFA.

\begin{tabular}{|c|c|c|c|c|c|}
\hline & $\begin{array}{l}1 \text { day } \\
(n=44)\end{array}$ & $\begin{array}{l}3 \text { day } \\
(n=44)\end{array}$ & $\begin{array}{l}1 \text { month } \\
(n=39)\end{array}$ & $\begin{array}{l}3 \text { month } \\
(n=29)\end{array}$ & $\begin{array}{l}6 \text { month } \\
(n=30)\end{array}$ \\
\hline $\begin{array}{l}\text { iPTH } \\
\text { (pg/mL) }\end{array}$ & $\begin{array}{l}11.55(1.50- \\
34.08)^{\star \star}\end{array}$ & $\begin{array}{l}24.50(11.80- \\
44.40)^{\star \star}\end{array}$ & $\begin{array}{l}64.30(53.70- \\
89.20)^{\star \star}\end{array}$ & $\begin{array}{l}58.20(49.70- \\
82.90)^{\star \star}\end{array}$ & $\begin{array}{l}45.35(33.50- \\
60.03)^{\star \star}\end{array}$ \\
\hline $\begin{array}{l}\text { Total Ca } \\
\text { (mmol/L) }\end{array}$ & $2.30 \pm 0.22^{\star \star}$ & $\begin{array}{l}2.23(2.19- \\
2.32)^{\star \star}\end{array}$ & $2.34 \pm 0.11^{\star \star}$ & $2.33 \pm 0.09 * *$ & $2.36 \pm 0.09 * *$ \\
\hline
\end{tabular}

\section{Efficacy after 6 months}

Thirty-two patients were followed up for more than 6 months, while 12 patients were lost to follow-up before 6 months. The median follow-up duration was 11.10 (6.30-14.25) months. Normal serum total $\mathrm{Ca}$ was achieved in 31 of 32 patients $(96.88 \%)$ at the last follow-up. Normal outcomes for both IPTH and Ca levels were achieved in 27 of the 32 patients (84.38\%) after RFA at the last follow-up (Fig. 2).

Images from a 69-year-old female with normocalcemic PHPT. (a) US examination revealed a $12.0 \times 6.0 \times 8.0 \mathrm{~mm}$ PHPT nodule inferior to the right lobe of the thyroid gland (arrows). (b) There was uniform hyperenhancement PHPT nodule on CEUS (arrows). (c) After Us-guided RFA, ultrasound images showed changes in echogenicity of ablated PHPT nodule (arrows). (d) After Us-guided RFA, nonenhancement area covered PHPT nodule shown on CEUS (arrows). On follow-up, the patient's serum iPTH decreased from $196.00 \mathrm{pg} / \mathrm{mL}$ to $54.30 \mathrm{pg} / \mathrm{mL}$ and total calcium changed from $2.41 \mathrm{mmol} / \mathrm{L}$ to $2.37 \mathrm{mmol} / \mathrm{L}$ at last follow-up (7.10 month) after RFA.

In these patients, the serum iPTH, total $\mathrm{Ca}$, phosphorus, and ALP levels significantly improved at last follow up after RFA (iPTH, 188.15 (141.30-363.88) pg/mL vs. 39.70 (31.38-54.60) pg/mL; calcium, 2.72 (2.61-2.83) $\mathrm{mmol} / \mathrm{L}$ vs. $2.36(2.29-2.41) \mathrm{mmol} / \mathrm{L}$; phosphorus, $0.85 \pm 0.14 \mathrm{mmol} / \mathrm{L}$ vs. $1.12 \pm 0.17$ 
mmol/L; ALP, 134.50 (89.25-245.00) U/L vs. 85.00 (72.00-104.00) U/L, respectively; all, $P<0.01$, Table 3). The remaining 5 patients had elevated iPTH levels at the last follow-up. One of the 5 patients had serum iPTH and Ca levels above the reference range with the presence of residual parathyroid glands shown on CEUS at the last follow-up. The other 4 patients only had increases in the serum iPTH levels. They had normal serum Ca levels and CEUS displayed no new abnormal lesions or residual parathyroid glands during the follow-up period.

Table 3

Serum iPTH, total Ca, phosphorus and ALP levels in baseline and post-RFA last follow-up comparison.

\begin{tabular}{|llll|}
\hline & $\begin{array}{l}\text { Before RFA } \\
(\mathbf{n = 3 2})\end{array}$ & $\begin{array}{l}\text { Last follow-up } \\
(\mathbf{n = 3 2})\end{array}$ & P Value \\
\hline iPTH $(\mathrm{pg} / \mathrm{mL})$ & $188.15(141.30-363.88)$ & $39.70(31.38-54.60)$ & $<0.001$ \\
\hline Total Ca $(\mathrm{mmol} / \mathrm{L})$ & $2.72(2.61-2.83)$ & $2.36(2.29-2.41)$ & $<0.001$ \\
\hline Phosphorus $(\mathrm{mmol} / \mathrm{L})$ & $0.85 \pm 0.14$ & $1.12 \pm 0.17$ & $<0.001$ \\
\hline ALP $(\mathrm{U} / \mathrm{L})$ & $134.50(89.25-245.00)$ & $85.00(72.00-104.00)$ & $<0.001$ \\
\hline $\begin{array}{l}\text { iPTH = intact parathyroid hormone, ALP = alkaline phosphatase, Total Ca = Total calcium. Phosphorus } \\
\text { values are presented as mean } \pm \text { standard deviation; iPTH, total calcium and ALP values are median } \\
\text { and interquartile range. Data were compared with paired-sample t tests or paired-sample Wilcoxon } \\
\text { signed-rank tests. }\end{array}$ & \multicolumn{2}{l}{} \\
\hline
\end{tabular}

\section{Laboratory analysis}

Significant differences in the serum total Ca levels were observed within 72 hours after treatment between the with hypocalcemia group $(n=13)$ and without hypocalcemia group $(n=31)(P<0.001)$. In the univariate analysis, pre-RFA serum iPTH and ALP levels were significantly difference between the two groups $(P<0.001$ and $P=0.001$, respectively). There were no significant different in age, sex, volume of ablated parathyroid gland, serum total $\mathrm{Ca}$, phosphorus, and $25(\mathrm{OH}) \mathrm{D}_{3}$ levels before RFA between the two groups. Patients with hypocalcemia tended to have higher preprocedural serum iPTH and ALP levels (Table 4).

Table 4

Comparison of pre-RFA variables between with hypocalcemia and without hypocalcemia Groups. 


\begin{tabular}{|c|c|c|c|c|}
\hline \multirow[t]{2}{*}{ Features } & & \multirow{2}{*}{$\begin{array}{l}\text { With hypocalcemia } \\
\text { group } \\
(n=13)\end{array}$} & Without hypocalcemia & \multirow{2}{*}{$\begin{array}{l}\mathrm{P} \\
\text { value }\end{array}$} \\
\hline & & & $(n=31)$ & \\
\hline \multirow[t]{2}{*}{ Gender } & male & 4 & 11 & \multirow[t]{2}{*}{1.000} \\
\hline & female & 9 & 20 & \\
\hline Age (y) & & $59.85 \pm 17.38$ & $57.87 \pm 14.00$ & 0.693 \\
\hline Volume (mL) & & $0.82(0.45-1.95)$ & $0.43(0.21-0.75)$ & 0.052 \\
\hline $25(\mathrm{OH}) \mathrm{D}_{3}(\mathrm{ng} / \mathrm{mL})$ & & $17.48 \pm 8.34$ & $15.19 \pm 5.79$ & 0.337 \\
\hline iPTH (pg/mL) & & $378.00(187-788.35)$ & $157.20(123.90-223.00)$ & 0.000 \\
\hline Total Ca (mmol/L) & & $2.74(2.63-3.13)$ & $2.71(2.56-2.82)$ & 0.354 \\
\hline $\begin{array}{l}\text { Phosphorus } \\
\text { (mmol/L) }\end{array}$ & & $0.83 \pm 0.13$ & $0.87 \pm 0.15$ & 0.473 \\
\hline ALP (U/L) & & $327(124.50-443.00)$ & $95.00(79.00-141.00)$ & 0.001 \\
\hline \multicolumn{5}{|c|}{$\begin{array}{l}\text { iPTH = intact parathyroid hormone, ALP = alkaline phosphatase, Total } \mathrm{Ca}=\text { Total calcium, } 25(\mathrm{OH}) \mathrm{D}_{3} \\
=25 \text {-hydroxyvitamin } \mathrm{D}_{3} .25(\mathrm{OH}) \mathrm{D}_{3} \text {, phosphorus values and age are presented as mean } \pm \text { standard } \\
\text { deviation; iPTH, total Ca, ALP values and volume are median and interquartile range. Gender is } \\
\text { displayed as a frequency. Continuous variables are compared with Mann-Whitney U test or Students t- } \\
\text { test; Categorical values are compared with Chi-square test. }\end{array}$} \\
\hline \multicolumn{5}{|c|}{$\begin{array}{l}\text { In the binary logistic regression analysis of iPTH and ALP values before RFA for the occurrence of } \\
\text { hypocalcemia, only the pre-ablative serum ALP level was significant. Pre-ablative ALP levels (odds } \\
\text { ratio [OR] }=1.011,95 \% \text { confidence interval [CI]: } 1.002-1.021, P=0.020 \text { ) were predictive factors for } \\
\text { hypocalcemia } 1-3 \text { days after RFA. When the ALP cut-off value was set at } 261.5 \mathrm{U} / \mathrm{L} \text { (area under the } \\
\text { curve }[\mathrm{AUC}]=0.824,95 \% \text { [CI]: } 0.673-0.974, \mathrm{P}=0.001 \text { ), the Youden index was } 0.615 \text {, and the predictive } \\
\text { sensitivity and specificity were } 61.5 \% \text { and } 100.0 \% \text {, respectively (Fig. } 3 \text { ). }\end{array}$} \\
\hline
\end{tabular}

ROC curve of ALP shows AUC of 0.824 , sensitivity of $61.5 \%$ and specificity of $100.0 \%$ using ALP cut-off point as $261.5 \mathrm{U} / \mathrm{L}$.

ROC $=$ Receiver operating characteristic,$A L P=$ alkaline phosphatase,$A U C=$ area under the curve

When we separated all patients into a high ALP group ( $\geq 261.5 \mathrm{U} / \mathrm{L} ; 8$ patients) and low ALP group (< $261.5 \mathrm{U} / \mathrm{L} ; 36$ patients) and compared total Ca levels between groups(Table 5), we found that post-RFA total Ca levels at 1 day 1, 3 days and 1 month were lower in the high ALP group than in the low ALP group (all, $P<0.05$ ). Mean total Ca levels at 3, 6 month and last follow up were not significantly different between the groups(Fig. 4).

Table 5

Total Ca levels before and after RFA in High ALP( $\geq 261.5$ U/L) and Low ALP Groups (<261.5 U/L). 


\begin{tabular}{|llll|}
\hline Total Ca $(\mathrm{mmol} / \mathrm{L})$ & Low ALP group & High ALP group & P Value \\
\hline Before RFA & $2.68(2.55-2.80)$ & $3.07(2.70-3.50)$ & 0.016 \\
\hline 1 Day after RFA & $2.31(2.19-2.44)$ & $2.03(2.01-2.15)$ & $<0.001$ \\
\hline 3 Day after RFA & $2.26(2.20-2.34)$ & $2.12(1.98-2.22)$ & 0.005 \\
\hline 1 month after RFA & $2.36 \pm 0.09$ & $2.24 \pm 0.13$ & 0.003 \\
\hline 3 month after RFA & $2.34 \pm 0.09$ & $2.31 \pm 0.11$ & 0.360 \\
\hline 6 month after RFA & $2.38 \pm 0.08$ & $2.30 \pm 0.10$ & 0.072 \\
\hline Last follow up & $2.36 \pm 0.08$ & $2.30 \pm 0.11$ & 0.126 \\
\hline
\end{tabular}

ALP = alkaline phosphatase, Total $\mathrm{Ca}=$ Total calcium. Total $\mathrm{Ca}$ values were median and interquartile range. Data are compared with Mann-Whitney U test or Students t-test.

Changes in serum total Ca levels classified according to whether seurm ALP $\geq 261.5 \mathrm{U} / \mathrm{L}$.

$\mathrm{ALP}=$ alkaline phosphatase, total $\mathrm{Ca}=$ total calcium. Total $\mathrm{Ca}$ values are median and interquartile range Data are compared with Mann-Whitney $U$ test. ${ }^{*} P<0.05$, ${ }^{\star *} \mathrm{P}<0.01$ compared between low ALP and high ALP groups.

Significant difference in serum iPTH levels were observed at 1 month after RFA between the ePTH group $(n=17)$ and normal PTH group $(n=21)(P<0.001)$. Conversely, serum total Ca levels decreased gradually and normalized in all patients in both groups. Upon univariate analysis, significant differences in pre-RFA serum iPTH and $25(\mathrm{OH}) \mathrm{D}_{3}$ levels between the ePTH and normal PTH groups were observed $(\mathrm{P}<0.001$ and $P=0.011$, respectively). In contrast, there were no significant different in age, sex, volume of ablated parathyroid gland, serum ALP, total $\mathrm{Ca}$, and phosphorus before RFA (Table 6).

Table 6

Comparison of pre-RFA variables between elevated PTH and normal PTH groups. 


\begin{tabular}{|c|c|c|c|c|}
\hline \multirow{2}{*}{ Features } & & \multirow{2}{*}{$\begin{array}{l}\text { Elevated group } \\
(n=17)\end{array}$} & \multirow{2}{*}{$\begin{array}{l}\text { Normal group } \\
(n=21)\end{array}$} & \multirow[t]{2}{*}{$P$ value } \\
\hline & & & & \\
\hline \multirow[t]{2}{*}{ Gender (number) } & male & 5 & 8 & \multirow[t]{2}{*}{0.575} \\
\hline & female & 12 & 13 & \\
\hline Age (y) & & $59.00 \pm 20.76$ & $57.14 \pm 10.66$ & 0.741 \\
\hline Volume (mL) & & $0.43(0.24-0.88)$ & $0.53(0.24-0.96)$ & 0.862 \\
\hline $25(\mathrm{OH}) \mathrm{D}_{3}(\mathrm{ng} / \mathrm{mL})$ & & $12.61 \pm 5.16$ & $18.47 \pm 7.06$ & 0.011 \\
\hline iPTH (pg/mL) & & $223.10(188.15-485.20)$ & 139.70(114-174.90) & 0.000 \\
\hline Total Ca (mmol/L) & & $2.82 \pm 0.38$ & $2.68 \pm 0.21$ & 0.183 \\
\hline Phosphorus (mmol/L) & & $0.86 \pm 0.15$ & $0.87 \pm 0.15$ & 0.906 \\
\hline ALP (U/L) & & $129.00(91.00-337.50)$ & $87.00(74.00,149.50)$ & 0.056 \\
\hline \multicolumn{5}{|c|}{$\begin{array}{l}\text { iPTH = intact parathyroid hormone, ALP = alkaline phosphatase, Total Ca = Total calcium, } 25(\mathrm{OH}) \mathrm{D}_{3} \\
=25 \text {-hydroxyvitamin } \mathrm{D}_{3} .25(\mathrm{OH}) \mathrm{D}_{3} \text {, phosphorus values and age are presented as mean } \pm \text { standard } \\
\text { deviation; iPTH, total Ca, ALP values and volume are median and interquartile range. Gender is } \\
\text { displayed as a frequency. Continuous variables are compared with Mann-Whitney } U \text { test or Students } t \\
\text { test; Categorical values are compared with Chi-square test. }\end{array}$} \\
\hline \multicolumn{5}{|c|}{$\begin{array}{l}\text { In binary logistic regression analysis, Pre-RFA } 25(\mathrm{OH}) \mathrm{D}_{3} \text { levels }([\mathrm{OR}]=0.783,95 \%[\mathrm{Cl}]: 0.655-0.936 \text {, } \\
\mathrm{P}=0.007) \text { and } \mathrm{PTH}([\mathrm{OR}]=1.008,95 \%[\mathrm{Cl}]: 1.001-1.015, \mathrm{P}=0.019) \text { were predictive factors } \\
\text { associated with the occurrence of ePTH at } 1 \text { month after RFA. The risk of ePTH decreased by } 21.7 \% \\
\text { for every } 1 \mathrm{ng} / \mathrm{mL} \text { increase in } 25(\mathrm{OH}) \mathrm{D}_{3} \text {. Serum iPTH level showed the best predictive value with the } \\
\text { cut-off value of } 172.4 \mathrm{pg} / \mathrm{mL}([\mathrm{AUC}]=0.839,95 \%[\mathrm{Cl}]: 0.707-0.971, \mathrm{P}<0.001) \text { followed by } 25(\mathrm{OH}) \mathrm{D}_{3} \\
([\mathrm{AUC}]=0.768,95 \%[\mathrm{Cl}]: 0.606-0.931, \mathrm{P}=0.008) \text {. When the iPTH cut-off value was set at } 172.4 \\
\mathrm{pg} / \mathrm{mL} \text {, the Youden index was } 0.644 \text {, and the predictive sensitivity and specificity were } 88.20 \% \text { and } \\
76.20 \% \text {, respectively (Fig. 5). Sixteen patients }(94.12 \%) \text { in ePTH gruop were followed up above } 6 \\
\text { months after RFA. Thirteen patients }(81.25 \%) \text { of them had mormal serum iPTH and total Ca levels at } \\
\text { last follow up. }\end{array}$} \\
\hline
\end{tabular}

ROC curve of iPTH shows AUC of 0.839 , sensitivity of $88.2 \%$ and specificity of $76.2 \%$ using iPTH cut-off point as $172.4 \mathrm{pg} / \mathrm{mL}$.

$\mathrm{ROC}=$ Receiver operating characteristic, $\mathrm{iPTH}=$ intact parathyroid hormone, $\mathrm{AUC}=$ area under the curve

\section{Safety and feasibility of US-guided RFA}

All patients tolerated the RFA. Hoarseness occurred in two patients caused by thermal ablation, both of them healed spontaneously within 2-3 months. Minor or swallowing pain occurred in 38 patients, and all of which were relieved naturally within 1-3 days. Within 72 hours after ablation, four patients had numbness and one patient had convulsions, which improved 1-3 days after the administration of oral and intravenous Ca supplements. There were no skin burns, hematomas, infections, permanent recurrent laryngeal nerve(RLN) injuries, or life-threatening complications during or after RFA. 


\section{Discussion}

Parathyroidectomy is recommended for both symptomatic and asymptomatic PHPT, as successful parathyroidectomy could make PHPT patients achieve long-term normocalcemia $(9,25)$. Our current study demonstrated that US-guided RFA also significantly decreased serum IPTH and ALP, and it normalized Ca and phosphorus levels with sustained efficacy in most patients with PHPT. Among patients who were followed for longer than 6 months, serum total Ca return to mormal range in 31 of 32 patients (96.88\%) and $\mathrm{IPTH}$ return to mormal range in 27 of 32 patients (84.38\%). In addition, one patient had P-PHPT and one had R-PHPT.

However, before satisfactory sustained efficacy was achieved, there were changing process about serum iPTH and calcium levels. Hypocalcemia is a common complication that occurs 1-3 days after thermal ablation(26). Hypocalcemia can manifest as numbness, paresthesia, and muscular twitching and in severe cases it may present with bronchospasm, cardiac arrhythmias, angina, heart failure, syncope, and seizures(27). Early identification of risk factors in patients with PHPT may ensure early identification and treatment of potential postoperative hypocalcemia, and may also ensure that serious sequelae are avoided. In our study, 13 of the 44 patients developed hypocalcemia within $72 \mathrm{~h}$ after ablation. Our current study also found that serum total Ca levels before RFA were significantly higher in patients with $A L P \geq 261.5 \mathrm{U} / \mathrm{L}$ than in patients with $A L P<261.5 \mathrm{U} / \mathrm{L}$ but for those patients with $A L P \geq 261.5 \mathrm{U} / \mathrm{L}$, serum total Ca levels were significantly lower in patients with with ALP $<261.5 \mathrm{U} / \mathrm{L}$ at 1 day, 3 days and 1 month after RFA (all, $P<0.05$ ). We believe that this was due to the fact that there was insufficient parathyroid function due to slow or delayed functional recovery of the remaining parathyroid tissue after ablation of the hyperfunctional PHPT nodule. Previous studies have demonstrated that serum ALP is a marker of bone formation and thus reflects the degree of osteoclastic activity and bone resorption. Bone resorption immediately decreases after surgery, but the changes in bone formation are not obvious over a short period(28). The high ALP value before ablation indicates that high bone turnover is associated with significant risk of hypocalcemia.

The iPTH measurements post-ablation immediate fall to undetectable or significantly lower levels suggests that the functional parathyroid gland was destroyed by RFA. Since the half-life of iPTH is short (4 min), serum iPTH rapidly decreases after RFA(29). The remaining parathyroid glands are temporarily suppressed following autonomous parathyroid tissue ablation. It takes suppressed parathyroid glands half an hour to several days to recover PTH secretion. The rapid return of PTH secretion may be caused by the direct response of the remaining parathyroid glands to hypocalcemia(30).

Previous studies showed that long-term elevation of PTH without hypercalcemia would linked to a spectrum of bone, kidney, and the cardiovascular system complications(31, 32). In the current study, the serum iPTH level was significantly elevated at 1 month post-ablation and the difference remained statistically significant compared with baseline levels. Seventeen of the 39 patients (43.59\%) developed ePTH 1 month after RFA. There were similar findings in patients treated with parathyroidectomy or thermal ablations in previous studies $(22,26)$. Possible hypotheses include incomplete ablation or the 
presence of ectopic parathyroid glands, vitamin D deficiency, renal resistance to PTH and a compensatory response to imbalance calcium homeostasis(33, 34). Fan et al.(35) found elevated serum iPTH levels at 1 month after MWA for PHPT, but their study did not investigate the risk factors for elevated iPTH levels with normocalcemia. Yen et al.(36) suggested that an elevated postoperative iPTH concentration does not predict surgical failure as measured by recurrent hypercalcemia. Carsello et al. (37) have shown that Patients with elevated PTH values after parathyroidectomy do not have greater rates of recurrence than patients with normal PTH values. In the current study, we compared the preablative clinical and laboratory data between the two groups. The ePTH group had higher iPTH and lower serum $25(\mathrm{OH}) \mathrm{D}_{3}$ levels before RFA than the normal group. Based on our results, a baseline serum iPTH level of more than $172.4 \mathrm{pg} / \mathrm{mL}$ could be considered a risk factor for ePTH at 1 month after RFA. A higher baseline level of iPTH indicates a longer-standing disease. In patients with a longer-standing disease, cortical bone remineralization lead to significant bone turnover after ablation. In order to maintain normal extracellular calcium concentration, so there is a compensatory increase in serum iPTH(38). In our study, a lower baseline $25(\mathrm{OH}) \mathrm{D}_{3}$ level was also a significant factor predicting ePTH after RFA. Untch et al.(39) demonstrated Patients in PHPT with vitamin D deficiency associated with higher baseline PTH levels and higher postoperative PTH levels. That is may be explained by vitamin D deficiency may be stimulate the secretion of serum iPTH. Based on our results, the serum iPTH tended to be stable and normal when the Ca level remained within normal range 3 months after RFA.

Additionally, the parathyroid glands are located behind the thyroid gland and are closely adjacent to the trachea and esophagus, the internal jugular vein and recurrent laryngeal nerve, and they are posterior to the long cervical and sympathetic nerves(40). Injury to the RLN is a serious complication after thyroid and parathyroid region thermal ablation or surgery $(13,41)$. In our study, 2 patients $(4.5 \%)$ developed temporary laryngeal nerve palsy and all of them recovered spontaneously within 2-3 months. No one had permanent RLN injury. The rate of permanent RLN injury has been reported to as close to $0 \%$ while temporary RLN injury is seen in $2.5 \%$ after parathyroidectomy $(42,43)$. The prevalence of permanent RLN injury observed in this study is consistent with previous studies but the rate of temporary laryngeal nerve palsy was slightly higher than those reported in previous studies. The main factor of slightly high temporary RLN injury rate may be related to potential thermal damage. Ultrasound imaging can show the ablated tissue as dynamic expanding echogenic region, which is helpful to identify the margins of the ablated lesion and reduce the collateral damage and local recurrence. To reduce the incidence of thermal injury of the recurrent laryngeal nerve, continuous injection of $5 \%$ dextrose solution should be performed during the ablation process to remove the potential thermal damage. Our method did not affect the volume of the ablation zone. Therefore, US-guided RFA is a safe and feasible method for clinical management of PHPT patients.

This study was subject to several limitations. First, the sample size was relatively small, which may have influenced the statistical analysis and validity of our findings. Second, the follow-up time was relatively short, and more follow-up time is necessary to determine the long-term effectiveness of the treatment of 
RFA for PHPT. Third, this was a non-randomized retrospective study, which may have induced selection bias.

In conclusion, US-guided RFA for patients with PHPT is safe and feasible. It may be an alternative treatment for patients with PHPT who refuse or are unsuitable for parathyroidectomy. The risk of ePTH decreased by $21.7 \%$ for every $1 \mathrm{ng} / \mathrm{mL}$ increase in $25(\mathrm{OH}) \mathrm{D}_{3}$. Significantly more patients developed hypocalcemia, ePTH when the pre-ablative ALP, iPTH were more than $261.5 \mathrm{U} / \mathrm{L}, 172.4 \mathrm{pg} / \mathrm{mL}$, respectively. More attention should be paid to serum $\mathrm{Ca}$ and $\mathrm{iPTH}$ levels after RFA in patients with higher serum iPTH and ALP levels and lower $25(\mathrm{OH}) \mathrm{D}_{3}$ levels before RFA.

\section{Declarations}

Acknowledgements:

This work was supported in part by technology planning project of Health Department of Zhejiang Province (No.2021KY018).

Author contributions:

H.H.C., C.Z.P. and Y.Z. wrote the main manuscript text; H.H.C., C.Z.P. and Y.Z. prepared all figures and tables; H.H.C., C.Z.P., Y.Z., R.Z.Y., Z.Z., Z.X.Z. , Q.H.H. and H.S.P. put forward the study design and analyzed data in this atudy; All authors approval of final version of submitted manuscript and agrees to ensure any questions related to the work are appropriately resolved.

Conflicts of Interest:

The authors declare no competing interests.

\section{References}

1. Bilezikian JP, Bandeira L, Khan A, Cusano NE. Hyperparathyroidism. Lancet. 2018;391:168-178. doi: 10.1016/S0140-6736(17)31430-7.

2. Zanocco KA, Yeh MW. Primary Hyperparathyroidism: Effects on Bone Health. Endocrinol Metab Clin North Am. 2017;46:87-104. doi: 10.1016/j.ecl.2016.09.012.

3. Makras P, Anastasilakis AD. Bone disease in primary hyperparathyroidism. Metabolism. 2018;80:5765. doi: 10.1016/j.metabol.2017.10.003.

4. Walker MD, Silverberg SJ. Primary hyperparathyroidism. Nat Rev Endocrinol. 2018;14:115-125. doi: 10.1038/nrendo.2017.104.

5. Wermers RA, et al. Incidence of primary hyperparathyroidism in Rochester, Minnesota, 1993-2001: an update on the changing epidemiology of the disease. J Bone Miner Res. 2006;21:171-7. doi: 10.1359/JBMR.050910. 
6. Yeh MW, et al. Incidence and prevalence of primary hyperparathyroidism in a racially mixed population. J Clin Endocrinol Metab. 2013;98:1122-9. doi: 10.1210/jc.2012-4022.

7. Fraser WD. Hyperparathyroidism. Lancet. 2009;374:145-58. doi: 10.1016/S0140-6736(09)60507-9.

8. Abdulla AG, Ituarte PH, Harari A, Wu JX, Yeh MW. Trends in the frequency and quality of parathyroid surgery: analysis of 17,082 cases over 10 years. Ann Surg. 2015 ;261:746-50. doi:

10.1097/SLA.0000000000000812.

9. Bilezikian JP, et al. Guidelines for the management of asymptomatic primary hyperparathyroidism: summary statement from the Fourth International Workshop. J Clin Endocrinol Metab. 2014;99:35619. doi: 10.1210/jc.2014-1413.

10. Elaraj D, Sturgeon C. Operative treatment of primary hyperparathyroidism: balancing costeffectiveness with successful outcomes. Surg Clin North Am. 2014;94:607-23. doi: 10.1016/j.suc.2014.02.011.

11. Nilsson IL. Primary hyperparathyroidism: should surgery be performed on all patients? Current evidence and residual uncertainties. J Intern Med. 2019;285:149-164. doi: 10.1111/joim.12840.

12. Andrioli M, Riganti F, Pacella CM, Valcavi R. Long-term effectiveness of ultrasound-guided laser ablation of hyperfunctioning parathyroid adenomas: present and future perspectives. AJR Am J Roentgenol. 201;199:1164-8. doi: 10.2214/AJR.11.8442.

13. Liu F, et al. Comparison of ultrasound-guided percutaneous microwave ablation and parathyroidectomy for primary hyperparathyroidism. Int J Hyperthermia. 2019;36(1):835-840. doi: 10.1080/02656736.2019.1645365.

14. Hänsler J, Harsch IA, Strobel D, Hahn EG, Becker D. Behandlung eines solitären Nebenschilddrüsenadenoms mit perkutaner ultraschallkontrollierter Radiofrequenzablation [Treatment of a solitary adenoma of the parathyroid gland with ultrasound-guided percutaneous Radio-Frequency-Tissue-Ablation (RFTA)]. Ultraschall Med. 2002;23:202-6. German. doi: 10.1055/s2002-33154.

15. Korkusuz H, Wolf T, Grünwald F. Feasibility of bipolar radiofrequency ablation in patients with parathyroid adenoma: a first evaluation. Int J Hyperthermia. 2018;34:639-643. doi: 10.1080/02656736.2018.1453552.

16. Kim BS, Eom TI, Kang KH, Park SJ. Radiofrequency ablation of parathyroid adenoma in primary hyperparathyroidism. J Med Ultrason (2001). 2014;41:239-43. doi: 10.1007/s10396-013-0501-0.

17. Khandelwal $\mathrm{AH}$, et al. Radiofrequency Ablation of Parathyroid Adenomas: Safety and Efficacy in a Study of 10 Patients. Indian J Endocrinol Metab. 2020;24:543-550. doi: 10.4103/ijem.IJEM_671_20.

18. Peng $\mathrm{C}$, et al. Efficacy and safety of ultrasound-guided radiofrequency ablation of hyperplastic parathyroid gland for secondary hyperparathyroidism associated with chronic kidney disease. Head Neck. 2017;39:564-571. doi: 10.1002/hed.24657.

19. Zeng Z, et al. Efficacy of Ultrasound-guided Radiofrequency Ablation of Parathyroid Hyperplasia: Single Session vs. Two-Session for Effect on Hypocalcemia. Sci Rep. 2020;10:6206. doi: 10.1038/s41598-020-63299-8. 
20. Loke SC, Tan AW, Dalan R, Leow MK. Pre-operative serum alkaline phosphatase as a predictor for hypocalcemia post-parathyroid adenectomy. Int J Med Sci. 2012;9:611-6. doi: 10.7150/ijms.4861.

21. Biskobing DM. Significance of elevated parathyroid hormone after parathyroidectomy. Endocr Pract. 2010;16:112-7. doi: 10.4158/EP09122.RA.

22. Yamashita $\mathrm{H}$, et al. Reelevation of parathyroid hormone level after parathyroidectomy in patients with primary hyperparathyroidism: importance of decreased renal parathyroid hormone sensitivity. Surgery. 2005;137:419-25. doi: 10.1016/j.surg.2004.12.009.

23. Ning L, Sippel R, Schaefer S, Chen $\mathrm{H}$. What is the clinical significance of an elevated parathyroid hormone level after curative surgery for primary hyperparathyroidism? Ann Surg. 2009;249:469-72. doi: 10.1097/SLA.0b013e31819a6ded.

24. Guerin C, et al. Persistent and recurrent hyperparathyroidism. Updates Surg. 2017;69:161-169. doi: 10.1007/s13304-017-0447-7.

25. Marcocci C, Bollerslev J, Khan AA, Shoback DM. Medical management of primary hyperparathyroidism: proceedings of the fourth International Workshop on the Management of Asymptomatic Primary Hyperparathyroidism. J Clin Endocrinol Metab. 2014;99:3607-18. doi: 10.1210/jc.2014-1417.

26. Wei Y, Peng L, Li Y, Zhao ZL, Yu MA. Clinical Study on Safety and Efficacy of Microwave Ablation for Primary Hyperparathyroidism. Korean J Radiol. 2020;21:572-581. doi: 10.3348/kjr.2019.0593.

27. Loke SC, et al. Efficacy of an intravenous calcium gluconate infusion in controlling serum calcium after parathyroidectomy for secondary hyperparathyroidism. Ann Acad Med Singap. 2009;38:107480.

28. Guo $\mathrm{CY}$, et al. Immediate changes in biochemical markers of bone turnover and circulating interleukin-6 after parathyroidectomy for primary hyperparathyroidism. Eur $\mathrm{J}$ Endocrinol. 2000;142:451-9. doi: 10.1530/eje.0.1420451.

29. Bieglmayer C, Prager G, Niederle B. Kinetic analyses of parathyroid hormone clearance as measured by three rapid immunoassays during parathyroidectomy. Clin Chem. 2002;48:1731-8.

30. Brasier AR, Wang CA, Nussbaum SR. Recovery of parathyroid hormone secretion after parathyroid adenomectomy. J Clin Endocrinol Metab. 1988;66:495-500. doi: 10.1210/jcem-66-3-495.

31. Vestergaard $H, \varnothing$ Stergaard Kristensen L. Normocalcemia and persistent elevated serum concentrations of 1-84 parathyroid hormone after operation for sporadic parathyroid adenoma: evidence of increased morbidity from cardiovascular disease. World J Surg. 2002;26:657-60. doi: 10.1007/s00268-001-0285-z.

32. Corbetta S. Normocalcemic Hyperparathyroidism. Front Horm Res. 2019;51:23-39. doi: 10.1159/000491036.

33. Lang BH, Wong IY, Wong KP, Lo CY. Eucalcemic parathyroid hormone elevation after parathyroidectomy for primary sporadic hyperparathyroidism: risk factors, trend, and outcome. Ann Surg Oncol. 2012;19:584-90. doi: 10.1245/s10434-011-1846-5. 
34. Mandal AK, Udelsman R. Secondary hyperparathyroidism is an expected consequence of parathyroidectomy for primary hyperparathyroidism: a prospective study. Surgery. 1998;124:1021-6. doi: $10.1067 /$ msy. 1998.92004 .

35. Fan BQ, He XW, Chen HH, Zhang WM, Tang W. US-guided microwave ablation for primary hyperparathyroidism: a safety and efficacy study. Eur Radiol. 2019;29:5607-5616. doi: 10.1007/s00330-019-06078-y.

36. Yen TW, Wilson SD, Krzywda EA, Sugg SL. The role of parathyroid hormone measurements after surgery for primary hyperparathyroidism. Surgery. 2006;140:665-72. doi: 10.1016/j.surg.2006.07.006.

37. Carsello CB, Yen TW, Wang TS. Persistent elevation in serum parathyroid hormone levels in normocalcemic patients after parathyroidectomy: does it matter? Surgery. 2012;152:575-81. doi: 10.1016/j.surg.2012.07.005.

38. Mittendorf EA, McHenry CR. Persistent parathyroid hormone elevation following curative parathyroidectomy for primary hyperparathyroidism. Arch Otolaryngol Head Neck Surg. 2002;128:275-9. doi: 10.1001/archotol.128.3.275.

39. Untch BR, Barfield ME, Dar M, Dixit D, Leight GS Jr, Olson JA Jr. Impact of 25-hydroxyvitamin D deficiency on perioperative parathyroid hormone kinetics and results in patients with primary hyperparathyroidism. Surgery. 2007;142:1022-6.

40. Mohebati A, Shaha AR. Anatomy of thyroid and parathyroid glands and neurovascular relations. Clin Anat. 2012;25:19-31. doi: 10.1002/ca.21220.

41. Chung SR, Baek JH, Choi YJ, Lee JH. Management strategy for nerve damage during radiofrequency ablation of thyroid nodules. Int J Hyperthermia. 2019;36:204-210. doi: 10.1080/02656736.2018.1554826.

42. Steurer $\mathrm{M}$, et al. Advantages of recurrent laryngeal nerve identification in thyroidectomy and parathyroidectomy and the importance of preoperative and postoperative laryngoscopic examination in more than 1000 nerves at risk. Laryngoscope. 2002;112:124-33. doi: 10.1097/00005537200201000-00022.

43. Périé $S$, et al. Value of recurrent laryngeal nerve monitoring in the operative strategy during total thyroidectomy and parathyroidectomy. Eur Ann Otorhinolaryngol Head Neck Dis. 2013;130:131-6. doi: 10.1016/j.anorl.2012.09.007.

\section{Figures}




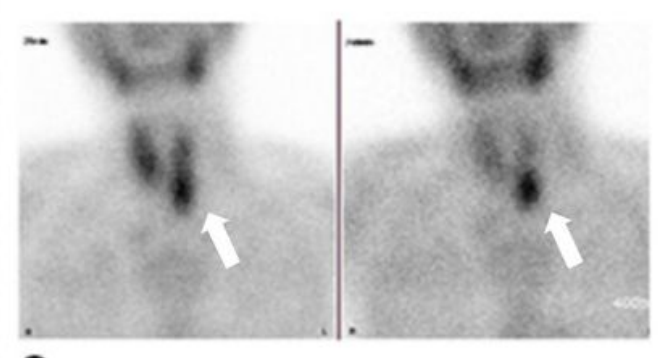

a.
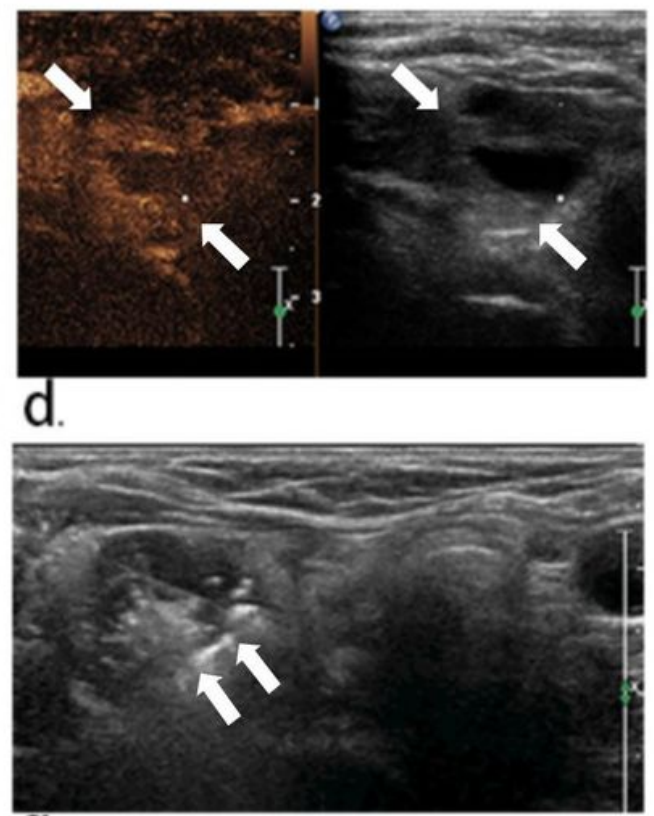

$\overline{9}$

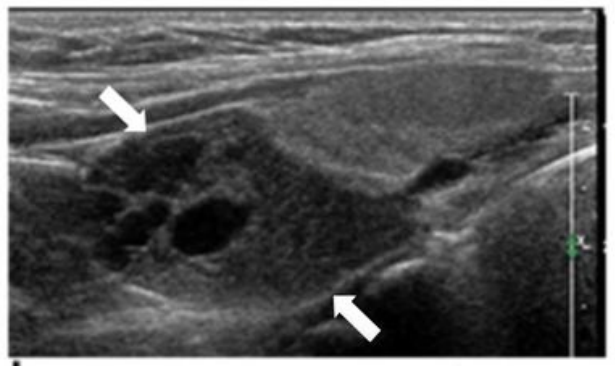

b.

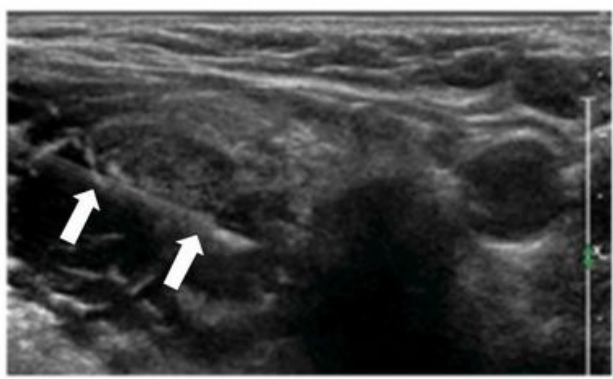

e.

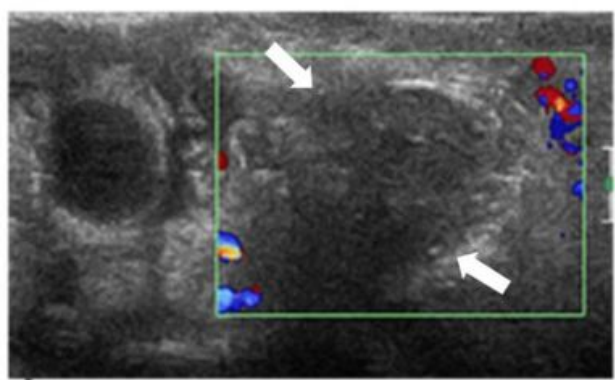

h.

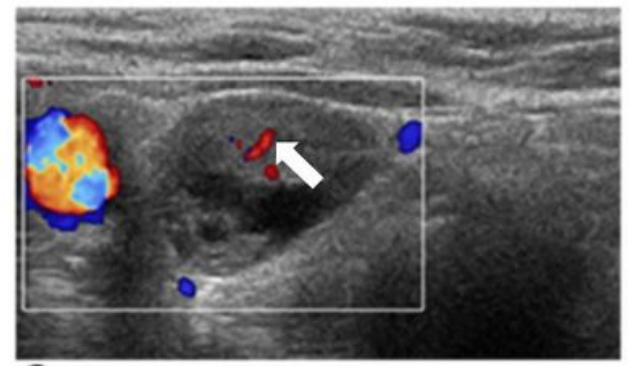

C.

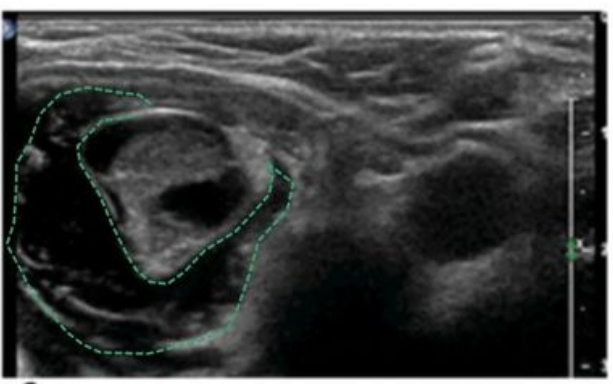

f.

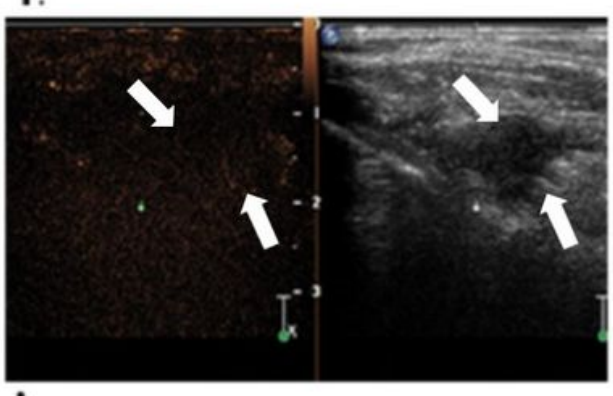

i.

\section{Figure 1}

Technical steps of Us-guided RFA. (a, b) First, technetium-sestamibi scan and US examination revealed a $29.6 \times 16.9 \times 13.1 \mathrm{~mm}$ PHPT nodule inferior to the right lobe of the thyroid gland (arrows). (c) Color doppler image shows abundant blood flow signals (arrows) in the PHPT nodule. (d) There was nonuniform hyperenhancement (arrows) PHPT nodule on CEUS. (e, f) Insertion of a 21-gauge needle (arrows) to inject $5 \%$ dextrose solution to create a safe distance $>5 \mathrm{~mm}$ in depth (green dotted line) between PHPT nodule and the vital structures of the neck. (g) Insertion of 18-gauge internally cooled electrode into the back of the PHPT nodule generates thermal energy and mobile ablation was performed with hyperechoic area (arrows) emerging inside nodule. (h) Color doppler image shows a significant reduction of the vascular signals (arrows) immediately after RFA. (i) When non-enhancement area covered PHPT nodule (arrows) on CEUS, treatment was ended. 

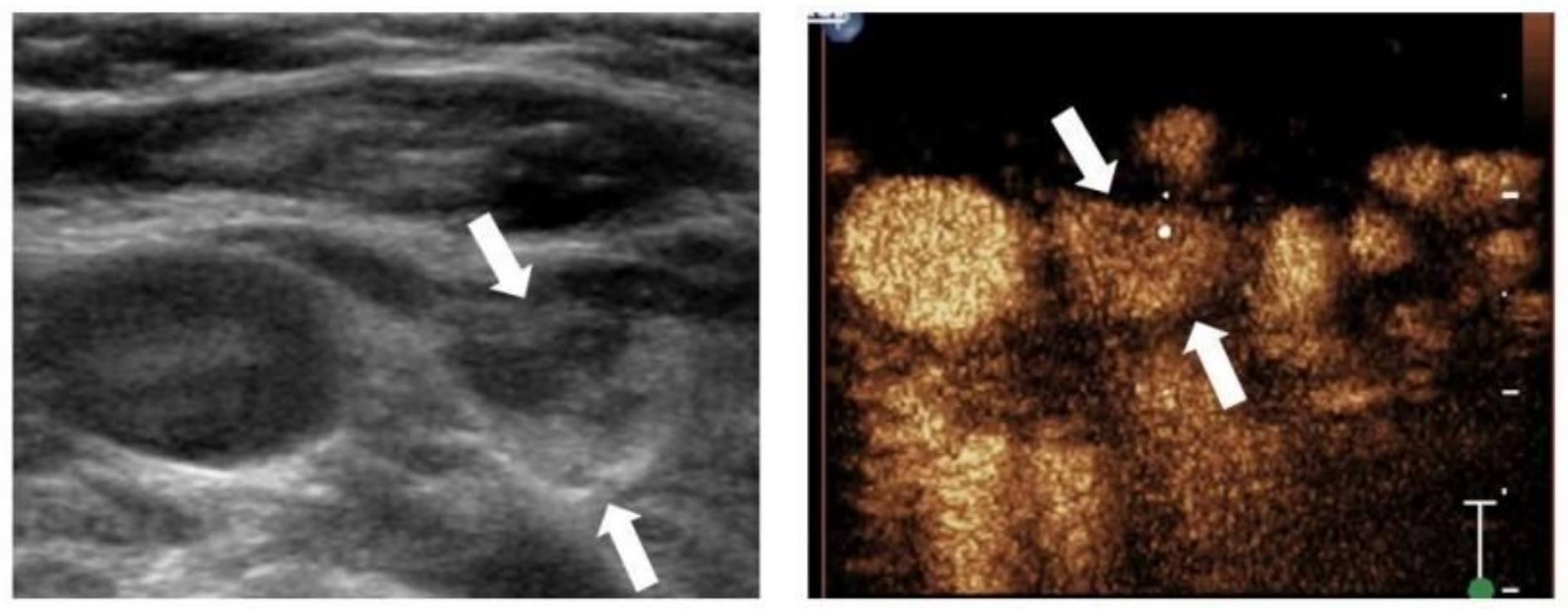

\section{a.}
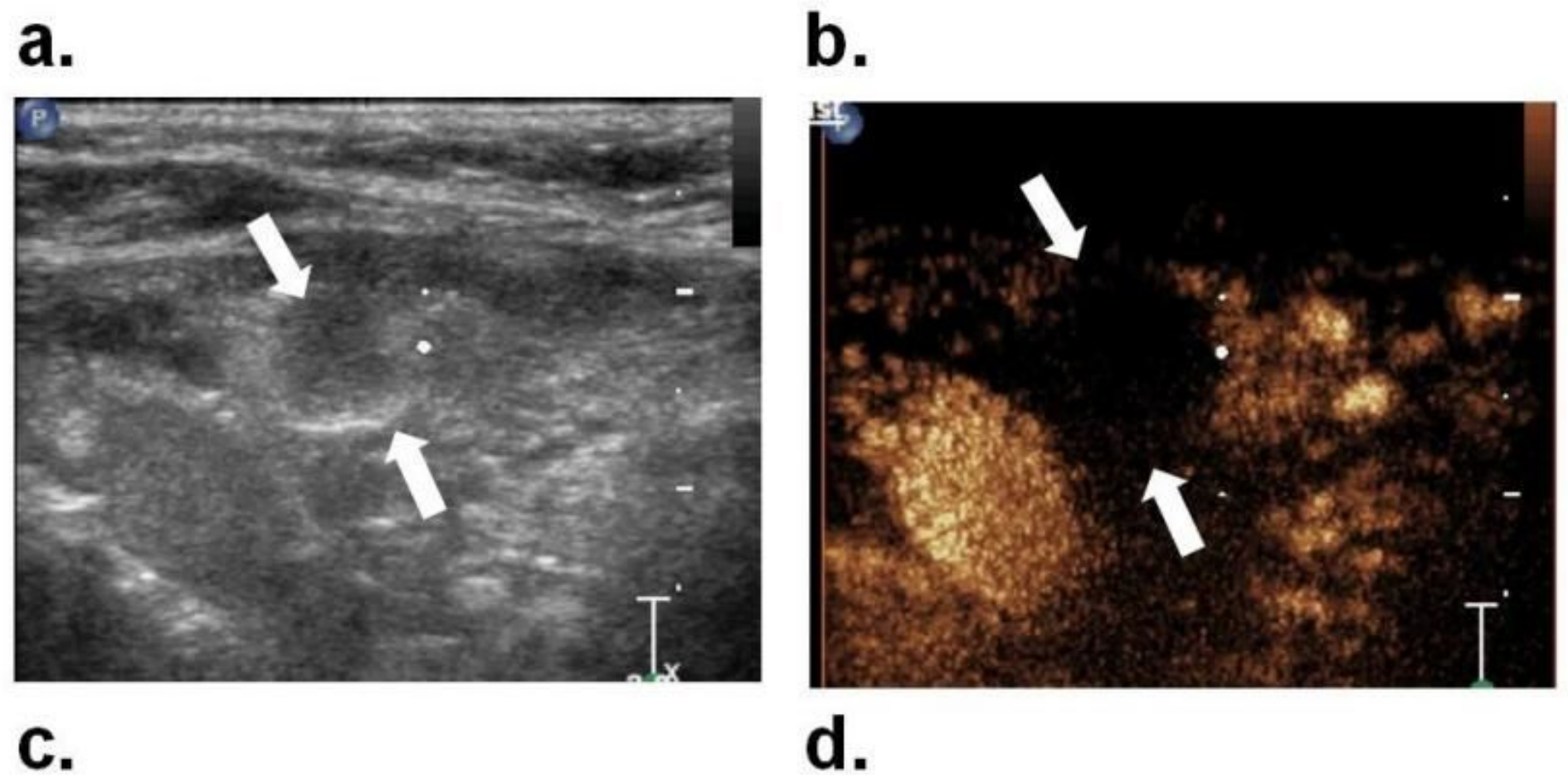

\section{C.}

\section{Figure 2}

Images from a 69-year-old female with normocalcemic PHPT. (a) US examination revealed a $12.0 \times 6.0 \times 8.0 \mathrm{~mm}$ PHPT nodule inferior to the right lobe of the thyroid gland (arrows). (b) There was uniform hyperenhancement PHPT nodule on CEUS (arrows). (c) After Us-guided RFA, ultrasound images showed changes in echogenicity of ablated PHPT nodule (arrows). (d) After Us-guided RFA, nonenhancement area covered PHPT nodule shown on CEUS (arrows). On follow-up, the patient's serum iPTH decreased from $196.00 \mathrm{pg} / \mathrm{mL}$ to $54.30 \mathrm{pg} / \mathrm{mL}$ and total calcium changed from $2.41 \mathrm{mmol} / \mathrm{L}$ to $2.37 \mathrm{mmol} / \mathrm{L}$ at last follow-up (7.10 month) after RFA. 


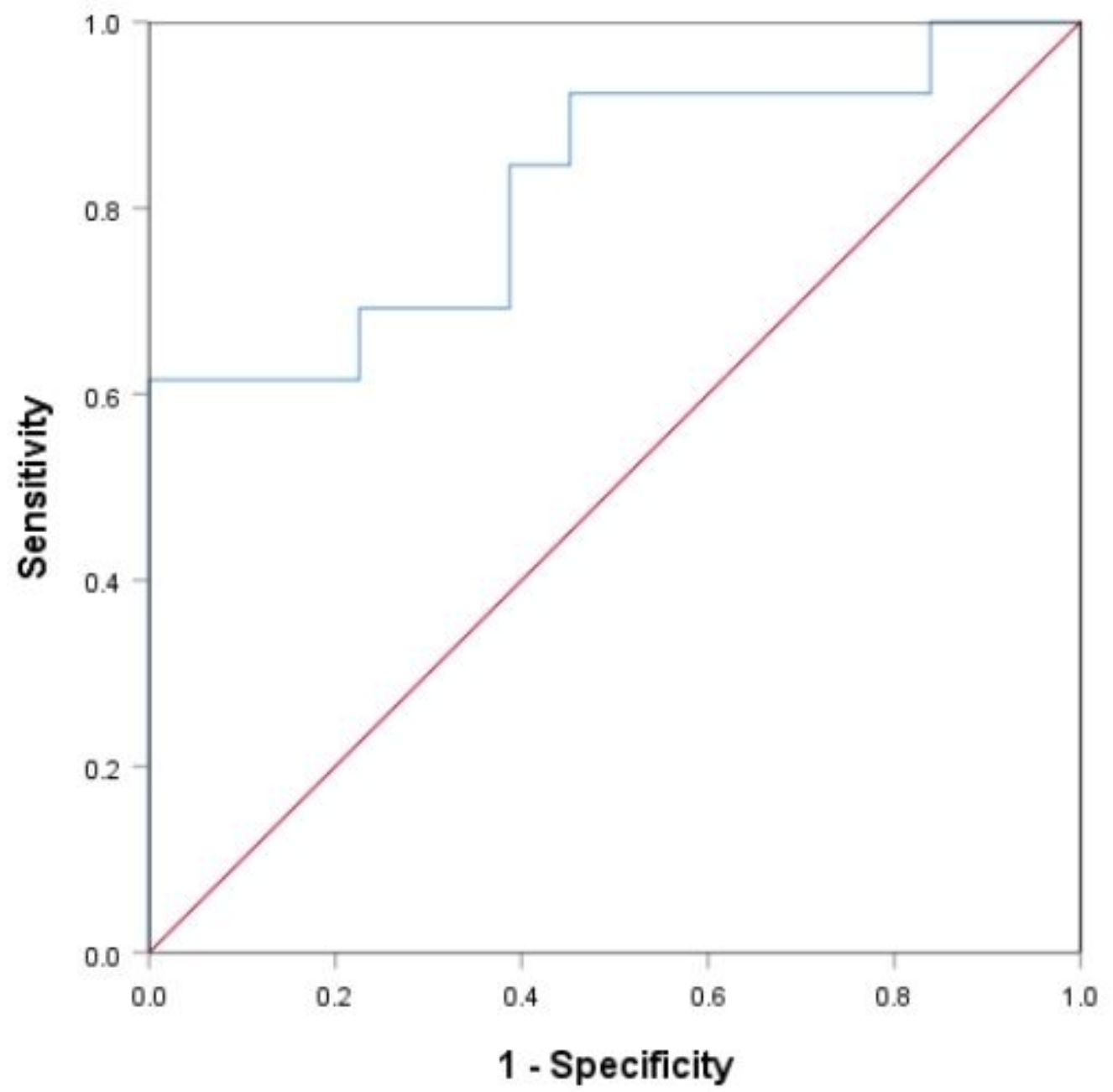

Figure 3

ROC curve of ALP shows AUC of 0.824 , sensitivity of $61.5 \%$ and specificity of $100.0 \%$ using ALP cut-off point as $261.5 \mathrm{U} / \mathrm{L}$. ROC = Receiver operating characteristic, ALP = alkaline phosphatase, AUC = area under the curve When we separated all patients into a high ALP group ( $\geq 261.5 \mathrm{U} / \mathrm{L} ; 8$ patients) and low ALP group ( $<261.5 \mathrm{U} / \mathrm{L} ; 36$ patients) and compared total Ca levels between groups(Table 5), we found that post-RFA total Ca levels at 1 day 1,3 days and 1 month were lower in the high ALP group than in the low ALP group (all, $\mathrm{P}<0.05$ ). 


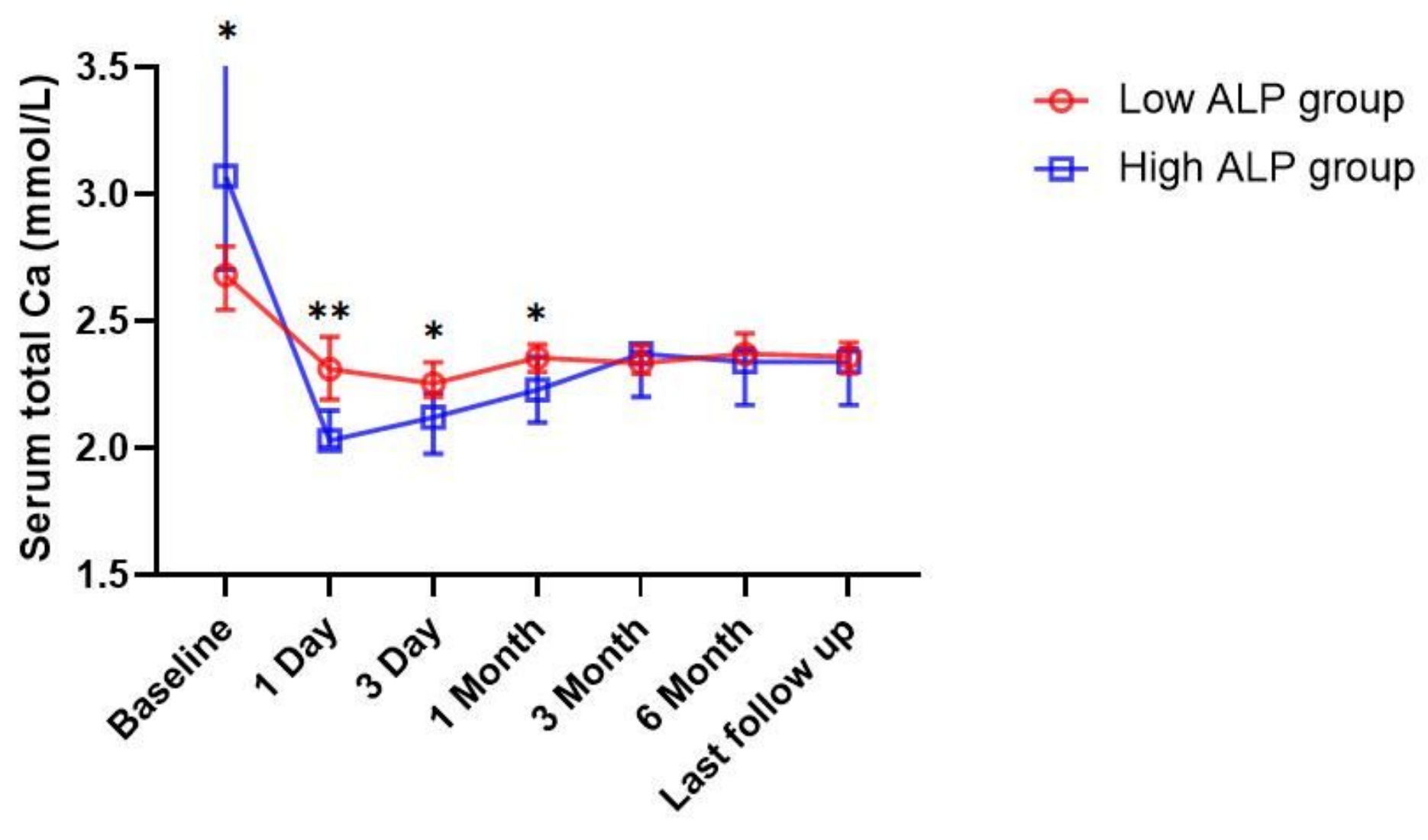

Time

Figure 4

Changes in serum total Ca levels classified according to whether seurm ALP $\geq 261.5 \mathrm{U} / \mathrm{L}$. ALP = alkaline phosphatase, total $\mathrm{Ca}=$ total calcium. Total $\mathrm{Ca}$ values are median and interquartile range. Data are compared with Mann-Whitney $\mathrm{U}$ test. ${ }^{*} \mathrm{P}<0.05,{ }^{* *} \mathrm{P}<0.01$ compared between low ALP and high ALP groups. 


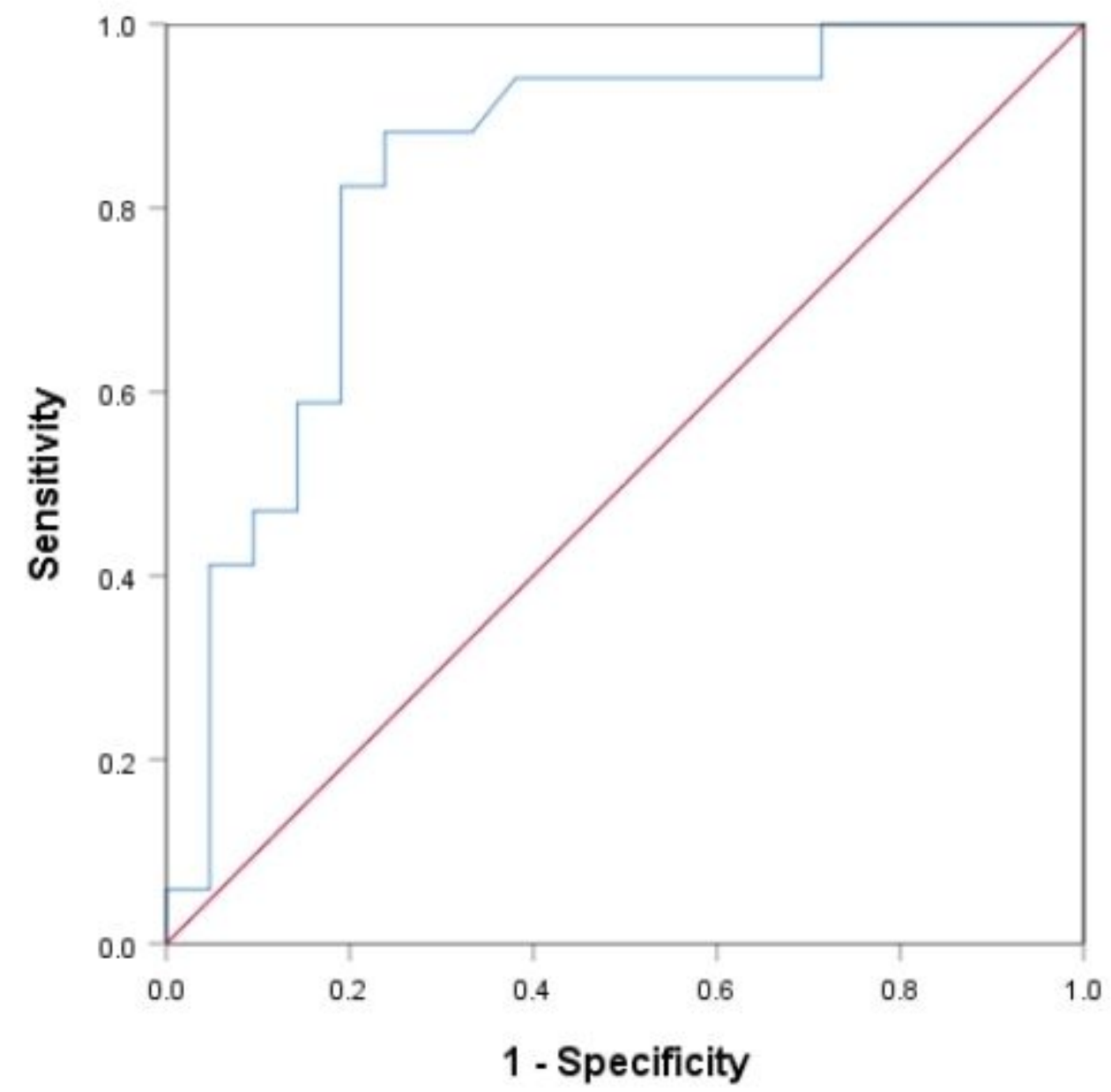

Figure 5

ROC curve of iPTH shows AUC of 0.839 , sensitivity of $88.2 \%$ and specificity of $76.2 \%$ using iPTH cut-off point as $172.4 \mathrm{pg} / \mathrm{mL}$. ROC = Receiver operating characteristic, $\mathrm{iPTH}=$ intact parathyroid hormone, $\mathrm{AUC}=$ area under the curve 